\title{
MCP-1 deficiency reduces susceptibility to atherosclerosis in mice that overexpress human apolipoprotein B
}

\author{
Jennifa Gosling, ${ }^{1}$ Sarah Slaymaker, ${ }^{1}$ Long Gu, ${ }^{2}$ Susan Tseng, ${ }^{2}$ Constance H. Zlot, ${ }^{1}$ \\ Stephen G. Young,,$^{1,3,4}$ Barrett J. Rollins, ${ }^{2}$ and Israel F. Charo ${ }^{1,3,4}$ \\ ${ }^{1}$ Gladstone Institute of Cardiovascular Disease, San Francisco, California 94141, USA \\ ${ }^{2}$ Department of Adult Oncology, Dana-Farber Cancer Institute, Harvard Medical School, Boston, Massachusetts 02115, USA \\ ${ }^{3}$ Cardiovascular Research Institute, and \\ ${ }^{4}$ Department of Medicine, University of California-San Francisco, San Francisco, California 94143, USA \\ Address correspondence to: Israel F. Charo, Gladstone Institute of Cardiovascular Disease, PO Box 419100, San Francisco, \\ California 94141-9100, USA. Phone: (415) 826-7500; Fax: (415) 285-5632; E-mail: icharo@gladstone.ucsf.edu
}

Received for publication October 26, 1998, and accepted in revised form January 26, 1999.

\begin{abstract}
The earliest recognizable atherosclerotic lesions are fatty streaks composed of lipid-laden macrophages (foam cells). Circulating monocytes are the precursors of these foam cells, but the molecular mechanisms that govern macrophage trafficking through the vessel wall are poorly understood. Monocyte chemoattractant protein-1 (MCP-1), a member of the chemokine (chemotactic cytokine) family, is a potent monocyte agonist that is upregulated by oxidized lipids. Recent studies in hypercholesterolemic mice lacking apo E or the low-density lipoprotein receptor have suggested a role for MCP-1 in monocyte recruitment to early atherosclerotic lesions. To determine if MCP-1 is critically involved in atherogenesis in the setting of elevated physiological plasma cholesterol levels, we deleted the MCP-1 gene in transgenic mice expressing human apo B. Here we report that the absence of MCP-1 provides dramatic protection from macrophage recruitment and atherosclerotic lesion formation in apo $B$ transgenic mice, without altering lipoprotein metabolism. Taken together with the results of earlier studies, these data provide compelling evidence that MCP-1 plays a critical role in the initiation of atherosclerosis.

J. Clin. Invest. 103:773-778 (1999).
\end{abstract}

\section{Introduction}

Fatty streaks, the earliest of atherosclerotic lesions, are largely composed of lipid-laden macrophages known as foam cells (1). Studies in swine (2) and macaques (3) have demonstrated that circulating blood monocytes are the precursors of these foam cells, but the chemoattractants that recruit these cells to the vessel wall are only now being identified.

Chemokines are low-molecular-mass (8-10 kDa) proteins that attract and activate leukocytes and are thought to play important roles in controlling inflammation. There are two major families of chemokines, CC and CXC, which differ in the positions of the first two of four conserved cysteines and in the types of leukocytes they attract. In general, the $\mathrm{CXC}$ chemokines are agonists for neutrophils, while the CC chemokines are agonists for mononuclear cells. Monocyte chemoattractant protein-1 (MCP-1) is a member of the CC family and is a potent agonist for monocytes, T lymphocytes, natural killer cells, and basophils (4). MCP-1 binds to and activates a seventransmembrane domain receptor known as CC chemokine receptor 2 (CCR2).

In cell culture systems, MCP-1 synthesis is upregulated by oxidized lipids (e.g., from oxidized lipoproteins; ref. 5) and by a variety of cytokines. Both in humans and in experimental animals, MCP-1 is expressed at high levels in macrophage-rich areas of atherosclerotic plaques (6-8). The fact that MCP-1 expression can be induced by oxidized lipoproteins and that MCP-1 is robustly expressed in atherosclerotic lesions suggests that MCP-1 expression could play a key role in recruiting monocytes/macrophages into early atherosclerotic lesions.

We recently assessed the role of CCR 2 activation by MCP-1 in atheroma formation in two genetically modified mouse models with increased susceptibility to atherosclerosis: apo E-deficient mice (9-11) and low-density lipoprotein (LDL) receptor-deficient mice (12-14). The absence of apo E or the LDL receptor in these mice causes marked retardation of the clearance of lipoproteins from the plasma, leading to hypercholesterolemia.

In the current study, we sought to assess the importance of the MCP-1/CCR2 axis in a mouse model characterized by an overproduction of atherogenic lipoproteins. To achieve this goal, we examined the effect of MCP-1 expression on the development of atherosclerotic lesions in mice that overproduce apo B $(15,16)$. Human apo B transgenic mice are characterized by a marked overproduction of apo B-containing lipoproteins in the liver, a mild elevation in plasma cholesterol levels, and an increased susceptibility to atherosclerosis on a high-fat diet. The lipoprotein profile in these mice is similar to that in most human subjects with premature atherosclerosis, exhibiting elevated levels of human apo B-containing LDL (17). In this study, we report that the absence of MCP-1 expression provides sustained protection from foam cell formation and atherosclerotic lesion development in transgenic mice that overproduce human apo B-containing lipoproteins. 


\section{Methods}

Genetically modified mice. Human apo B transgenic mice generated with an $80-\mathrm{kb}$ fragment of genomic DNA $\left(\mathrm{HuBTg}^{+/ 0}\right)$ have been described and characterized previously $(15,16)$. The genetic background of these mice was $~ 93 \% \mathrm{C} 57 \mathrm{Bl} / 6$ and $\sim 7 \%$ SJL. MCP-1 knockout mice have been described previously (ref. 14; the gene encoding MCP-1 in the mouse is named $S c y A 2$, but the genotype of these mice will be denoted $M C P-1^{-1-}$ for convenience). The genetic background of these mice was $\sim 93 \% \mathrm{C} 57 \mathrm{Bl} / 6$ and $\sim 7 \% 129 / \mathrm{Sv})$. Male $M C P-1^{+/-}$mice were crossed with female $\mathrm{HuBTg}^{+/ 0}$ mice to generate double heterozygotes $\left(\mathrm{MCP}-1^{+/-} \mathrm{HuBTg}^{+/ 0}\right)$. The latter mice were intercrossed to generate human apo B transgenic mice that were homozygous for the MCP-1 knockout mutation (MCP$\left.1^{-/-} \mathrm{HuBTg}^{+/ 0}\right)$ and littermate controls that carried the human apo B transgene but were wild-type at the MCP-1 locus (MCP$\left.1^{+/+} \mathrm{HuBTg}^{+/ 0}\right)$. Genotyping was performed by Southern blot analysis of genomic DNA prepared from tail biopsies (15).

The animals were maintained in a pathogen-free barrier facility with a 12-h light/12-h dark cycle and had free access to food and water. The mice were weaned to a chow diet 21 days after birth and were placed on a high-fat diet $(16,18)$ containing $1.25 \%$ cholesterol and $0.05 \%$ sodium cholate (ICN Biochemicals, Aurora, Ohio, USA) at $6-8$ weeks of age. The mice were maintained on the high-fat diet for 9,15 , or 18 weeks before they were sacrificed for analysis of atherosclerotic lesions. Study animals were female, and there were eight or more mice in each group.

Lipid measurements. Serum was collected from all mice at the time of sacrifice. Plasma was collected at the 15 -week time point in tubes containing $1.0 \mathrm{mM}$ EDTA and $113 \mathrm{KIU} / \mathrm{ml}$ aprotinin (ICN Biochemicals) for measurement of triglycerides. For both the plasma and serum samples, the total cholesterol and high-density lipoprotein (HDL) cholesterol levels were measured, in duplicate, with a colorimetric assay $(15,19)$. Total plasma triglycerides were measured in fresh plasma samples with a colorimetric assay (GPO triglyceride kit; Boehringer Mannheim GmbH, Mannheim, Germany) $(15,19)$.

Analysis of lipid distribution within the plasma lipoproteins. The distribution of plasma cholesterol and triglycerides within the plasma lipoprotein fractions was assessed by fast-protein liquid chromatography (FPLC) $(15,16,19)$. For these experiments, plasma samples from four or more mice of each genotype were pooled and size-fractionated on a Superose 6 HR 10/30 column (Pharmacia Biotech Inc., Piscataway, New Jersey, USA) at a flow rate of 0.4 $\mathrm{ml} / \mathrm{min}$; fractions of $0.5 \mathrm{ml}$ were collected.

Immunoassays. Plasma levels of human and mouse apo B100 were measured by competitive radioimmunoassays as described (20-23). High-binding, 96-well, flat-bottom polypropylene plates (Nunc A/S, Roskilde, Denmark) were coated with LDL $(1 \mu \mathrm{g} / \mathrm{ml})$ for $4 \mathrm{~h}$ at room temperature, blocked with $2 \%$ BSA in PBS, and washed four times with SPRIA (PBS with $0.1 \%$ BSA, $0.05 \%$ Tween- 20 , and $0.08 \%$ sodium azide). Plasma samples were diluted with PBS, added to the wells, and incubated overnight with ${ }^{125}$ I-labeled antibodies against murine apo B-100 (23) or human apo B-100 (22). Bound antibody was quantitated by counting gamma emissions (model 8000; Beckman Instruments, Fullerton, Callifornia, USA), and apo B-100 levels were determined from a standard curve. In addition to the competitive immunoassays, mouse apo B-100 levels were also determined with a monoclonal antibody-based, solid-phase sandwich immunoassay (23-26).

Quantitation of atherosclerotic lesions. The heart and proximal aorta were harvested as described $(16,27)$, except that the mice were perfused first with PBS and then with freshly prepared 3\% paraformaldehyde in PBS, and the tissues were equilibrated in $20 \%$ sucrose for a minimum of $2 \mathrm{~h}$, embedded in OCT, and frozen. Cryosections $(10 \mu \mathrm{m})$ were cut, and the extent of atherosclerosis was measured by quantification of oil red O staining of serial sections as described $(16,27)$. Sections used for analysis spanned a total of $550 \mu \mathrm{m}$, centered on the orifice of the left coronary artery. Image analysis was performed with the Image-1/AT system (Universal Imaging Corp., West Chester, Pennsylvania, USA) by two persons blinded to the genotypes $(16,27)$.

Immunohistochemistry. Serial cryosections $(10 \mu \mathrm{m})$ were collected at $50-\mu \mathrm{m}$ intervals. The endogenous peroxidase activity was neutralized with $\mathrm{H}_{2} \mathrm{O}_{2}(0.3 \% \mathrm{vol} / \mathrm{vol})$ for $10 \mathrm{~min}$ at $25^{\circ} \mathrm{C}$, and the sections were blocked with BSA $(3 \% \mathrm{wt} / \mathrm{vol}$ in PBS and $20 \mathrm{mM}$ glycine) for $45 \mathrm{~min}$ at $25^{\circ} \mathrm{C}$. Serial sections were stained overnight with MOMA-2 (BioSource International, Camarillo, California, USA; 1:400 dilution in PBS and $20 \mathrm{mM}$ glycine at $4^{\circ} \mathrm{C}$ ), a monoclonal antibody specific for murine monocytes/macrophages, as described (11). After washing, a goat anti-rat biotinylated secondary antibody (PharMingen, San Diego, California, USA) was added, followed by streptavidin-horseradish peroxidase (PharMingen) (11). The signal was enhanced with a tyramide signal amplification (TSA) kit (NEL 702; Du Pont NEN Research Products, Boston, Massachusetts, USA) according to the manufacturer's protocol, and sections were counterstained for nuclei with SYTOX Green from Molecular Probes Inc. (Eugene, Oregon, USA).

Statistical analysis. To analyze differences in lipid measurements and the extent of atherosclerosis, the $t$ test and MannWhitney U tests were performed with InStat 2.01 software (GraphPad Software for Science Inc., San Diego, California, USA) for Macintosh.

\section{Results}

Atherosclerotic lesion formation in MCP-1-deficient mice. To place the MCP-1 deletion on an atherogenic background, we crossed MCP-1 knockout mice with human apo B transgenic $\left(\mathrm{HuBTg}^{+/ 0}\right)$ mice. HuBTg ${ }^{+/ 0}$ mice develop dietdependent atherosclerotic lesions, clustered primarily in the proximal aorta (16). We then quantified the extent of atherosclerotic lesions in microscopic sections of the proximal aorta in two groups of human apo B transgenic mice: one group homozygous for the MCP-1 knockout muta-

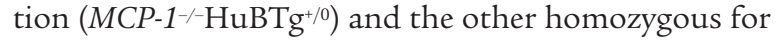
the wild-type MCP-1 allele (MCP-1 $\left.{ }^{+/+} \mathrm{HuBTg}^{+/ 0}\right)$.

At each time point examined, the absence of MCP-1 expression significantly reduced the extent of atherosclerosis (Fig. 1). After nine weeks on the high-fat diet, the mean lesion area was $64,606 \mu \mathrm{m}^{2}$ in the $M C P$ $1^{+/+} \mathrm{HuBTg}^{+/ 0}$ mice and $25,886 \mu \mathrm{m}^{2}$ in littermate $\mathrm{MCP}$ -

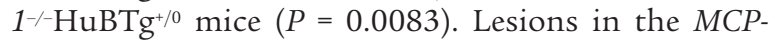
$1^{+/+} \mathrm{HuBTg}^{+/ 0}$ mice progressed steadily with time, whereas lesion progression in the $\mathrm{MCP}-1^{-/-} \mathrm{HuBTg}^{+/ 0}$ mice was markedly attenuated in comparison: mean lesion size in the $\mathrm{MCP-1/-} \mathrm{HuBTg}^{+/ 0}$ mice was $70 \%$ smaller at 15 weeks $(P=0.0001)$ and $60 \%$ smaller at 18 weeks $(P=0.0009)$.

Immunocytochemistry. Representative oil red $\mathrm{O}$-stained sections from mice fed the high-fat diet for 18 weeks are shown in Fig. 2. In general, the lesions were both thinner and less extensive in the $M C P-1^{-/-} \mathrm{HuBTg}^{+/ 0}$ mice than in the $\mathrm{MCP}-1^{+/+} \mathrm{HuBTg}^{+/ o}$ mice. We next sought to determine if the decrease in lesion size in the MCP-1-deficient mice was due to a reduction in macrophage recruitment to the vessel wall. Sections from $M C P-1^{-/} \mathrm{HuBTg}^{+/ 0}$ and $M C P-1^{+/+} \mathrm{HuBTg}^{+/ 0}$ mice on the high-fat diet for 15 weeks 
were stained for macrophages with MOMA-2. As shown in Fig. 3, the macrophage content was significantly reduced in the absence of MCP-1. Moreover, at this relatively early time point, the vast majority of the oil red $\mathrm{O}$-positive area appeared to be composed of lipid-laden, MOMA-2-positive macrophages.

Lipoprotein analysis. Lesion size in murine models of atherosclerosis is dependent on the levels of both total cholesterol (27) and HDL cholesterol (28-30). To determine if the deletion of the MCP-1 gene altered plasma lipid metabolism, plasma lipid and lipoprotein levels were measured, and the distribution of lipids within the plasma lipoproteins was assessed by fastprotein liquid chromatography. As shown in Fig. 4, and as reported previously (31), the $\mathrm{MCP}-1^{-/-}$human apo $B$ transgenic mice had higher levels of intermediate-density lipoproteins and LDL than nontransgenic littermates. Deletion of MCP-1 had no significant effect on the levels of total cholesterol, HDL cholesterol, and triglycerides, or on the lipoprotein profile (Table 1 and Fig. 4). In addition, the MCP-1 knockout mutation did not alter the plasma levels of human or mouse apo B-100 (data not shown).

\section{Discussion}

This study demonstrates that MCP-1 promotes the development of early atherosclerotic lesions. At each time point examined, MCP-1-deficient mice had less macrophage infiltration of the proximal aorta, and markedly smaller lesion areas than littermate control mice. Significantly, these effects were independent of alterations in cholesterol metabolism. Taken together with the results of very recent studies $(11,14)$, these new data provide compelling evidence that MCP-1 plays a pivotal role in fatty streak formation.

Most inbred strains of mice do not develop atherosclerotic lesions, even when fed a high-fat, high-cholesterol diet (32-34). However, in recent years, atherosclerosis-susceptible mice have been created by either knocking out or overexpressing key genes in lipoprotein metabolism. Each of these mouse models has specific advantages and disadvantages. Mice deficient in apo E (Apoe-/-) have defective clearance of lipoproteins from the plasma; consequently, they have very high plasma cholesterol levels $(\sim 500 \mathrm{mg} / \mathrm{dl})$ on a chow diet and even higher levels $(\sim 2,000 \mathrm{mg} / \mathrm{dl})$ on a high-fat diet $(10,35-37)$. The majority of the cholesterol in the plasma of Apoe $e^{-/}$mice is carried on very-low-density lipoprotein (VLDL) particles, whereas in humans, the majority of the cholesterol is carried on LDL particles. In addition, most of the cholesterol in $A p o e^{-/-}$mice is

\section{Table 1}

Cholesterol and triglyceride levels in mice on the high-fat diet

\begin{tabular}{lcccc}
\hline Genotype & Weight & Total cholesterol & $\begin{array}{c}\text { Total triglyceride } \\
\mathrm{mg} / \mathrm{dl}\end{array}$ & HDL cholesterol \\
& $\mathrm{g}$ & & $73 \pm 15$ & \\
$\mathrm{MCP}-1^{+/+} \mathrm{HuB} \mathrm{Tg}^{+/ 0}$ & $26.6 \pm 3.3$ & $354 \pm 67$ & $70 \pm 10$ \\
$\mathrm{MCP}-1^{-/} \mathrm{HuB} \mathrm{Tg}^{+/ 0}$ & $26.2 \pm 2.7$ & $415 \pm 54$ & $68 \pm 12$ & $39 \pm 10$ \\
\hline
\end{tabular}

Values are mean $\pm \mathrm{SD}(n=5$ animals in each group), at the 15 -week time point. Total triglyceride and HDL cholesterol levels were measured in freshly isolated plasma, and total cholesterol was measured in serum. Statistical analysis (Mann Whitney) revealed no differences between the groups. carried on apo B-48-containing particles, and the levels of apo B-100 in the plasma are actually very low. In contrast, apo B-100 is the major cholesterol-carrying protein in human plasma, and apo B-48 levels are extremely low. Apo E-deficient mice develop severe atherosclerotic lesions on a chow diet, particularly in the proximal aorta, and lesion development is accelerated and widespread if the animals are fed a high-fat diet $(35,37)$. We believe that Apoe-/- mice are a useful model for investigating rapidly progressing atherosclerotic lesions in the setting of severe hypercholesterolemia. We recently demonstrated that apo E-deficient mice have decreased atheroma formation in the setting of hypercholesterolemia and a deficiency of CCR2, the receptor for MCP-1 (11).

The LDL receptor-deficient mouse ( $\left.L d l^{-/-}\right)$is another useful model for atherosclerosis studies $(13,38)$. A deficiency in LDL receptor expression also interferes with the clearance of lipoproteins from the plasma and results in a striking accumulation of LDL cholesterol. In humans, mutations in the LDL receptor gene cause familial hypercholesterolemia, a severe form of the disease additionally characterized by premature atherosclerosis. On a chow diet, $L d l r^{-/}$mice have only mildly elevated LDL cholesterol levels and develop only minimal atherosclerotic lesions. Production of significant atherosclerotic lesions in $L d l r$ - mice requires a high-fat diet, which results in severe hypercholesterolemia (13). However, when $L d l r^{-}$- mice are fed a high-fat diet, a large fraction of the cholesterol is contained in large, VLDLsized particles rather than in the LDL (13). In a recent study, Gu et al. (14) generated LDL receptor-deficient mice that were also deficient in MCP-1 ( $\left.\mathrm{Ldlr} /-\mathrm{MCP}-\mathrm{1}^{-/-}\right)$ and fed them a high-fat diet. Significantly, those mice manifested a marked reduction in atherosclerotic lesions compared with LDL receptor-deficient mice expressing normal levels of MCP-1 (14).

Most humans with atherosclerosis do not have severe hypercholesterolemia or mutations in lipoproteins or receptors that lead to defects in lipoprotein clearance. Rather, they have only mildly increased plasma levels of LDL cholesterol and apo B. This "garden variety" lipoprotein abnormality (frequently called hyperapobetalipoproteinemia) is thought to be caused by increased apo B production rates (39-41). Although earlier studies had established a role for MCP-1 in early atheroma formation, they did so in murine models with high plasma cholesterol levels. A complicating factor in these studies was the possibility that the extremely high plasma cholesterol levels might induce synthesis of MCP-1 and thereby result in atherosclerotic lesion formation that was artificially MCP-1-dependent. It was important, therefore, to evaluate the role of MCP-1 in an animal in which cholesterol levels were only moderately elevated. Human apo B transgenic mice $(16,17,42)$ have significantly increased apo B production rates (17) but, unlike apo E-deficient mice, have relatively low plasma 


\section{Figure 1}

Atherosclerotic lesion area in MCP- $1^{+/+} \mathrm{HuBTg}^{+/ 0}$ and $M C P-1^{-/-} \mathrm{HuBTg}^{+/ 0}$ mice. Microscopic cross sections $(10 \mu \mathrm{m})$ of the proximal aortic root were stained with oil red $\mathrm{O}$ to reveal lipids and quantitated by digital morphometry. Each symbol represents the average lesion area of a single animal; the bar indicates the mean of the group. At each time, MCP$1^{+/+} \mathrm{HuBTg}^{+/ 0}$ mice had a significantly larger mean lesion area than MCP-

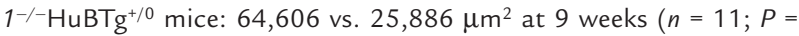
$0.0083) ; 185,772$ vs. $53,027 \mu \mathrm{m}^{2}(n \geq 9 ; P=0.0001)$ at 15 weeks; and 305,790 vs. $123,025 \mu \mathrm{m}^{2}$ at 18 weeks $(n \geq 8 ; P=0.0009)$. MCP-1, monocyte chemoattractant protein-1.

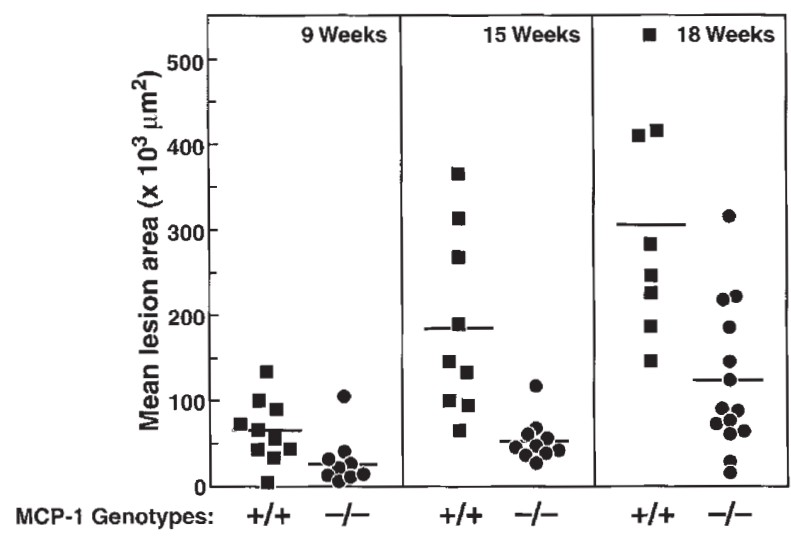

$L d l r^{-/-M C P-1^{-/-}}$mice than in the $L d l r^{/-} \mathrm{MCP}-1^{+/+}$mice, and this reduction was sustained after 20-25 weeks on a high-fat diet (14). The results of the current study, in which a $60 \%-70 \%$ lesion reduction was maintained for 18 weeks, are thus more similar to those of the LDL receptor-deficient model. The reason for this difference is not clear. We speculate that the more marked hypercholesterolemia in the apo E-deficient mice induces the synthesis and secretion of other chemokines, which might recruit monocytes to the arterial wall independently of MCP-1. Alternatively, the difference may be due to the fact that studies involving the LDL receptor knockout mice and the human apo B transgenic mice used MCP-1-deficient animals, whereas the study using apo E-deficient mice utilized mice deficient in CCR2. If MCP-1 were to activate receptors other than CCR2, one might reasonably predict that the absence of MCP-1 would be more atheroprotective than the absence of CCR2. Although molecular descriptions of functional receptors for MCP-1 other than CCR2 are lacking, it is conceivable that such receptors could be induced by hypercholesterolemia. (11). In contrast, in LDL receptor-deficient mice, extent of atherosclerosis was $\sim 80 \%$ lower in the

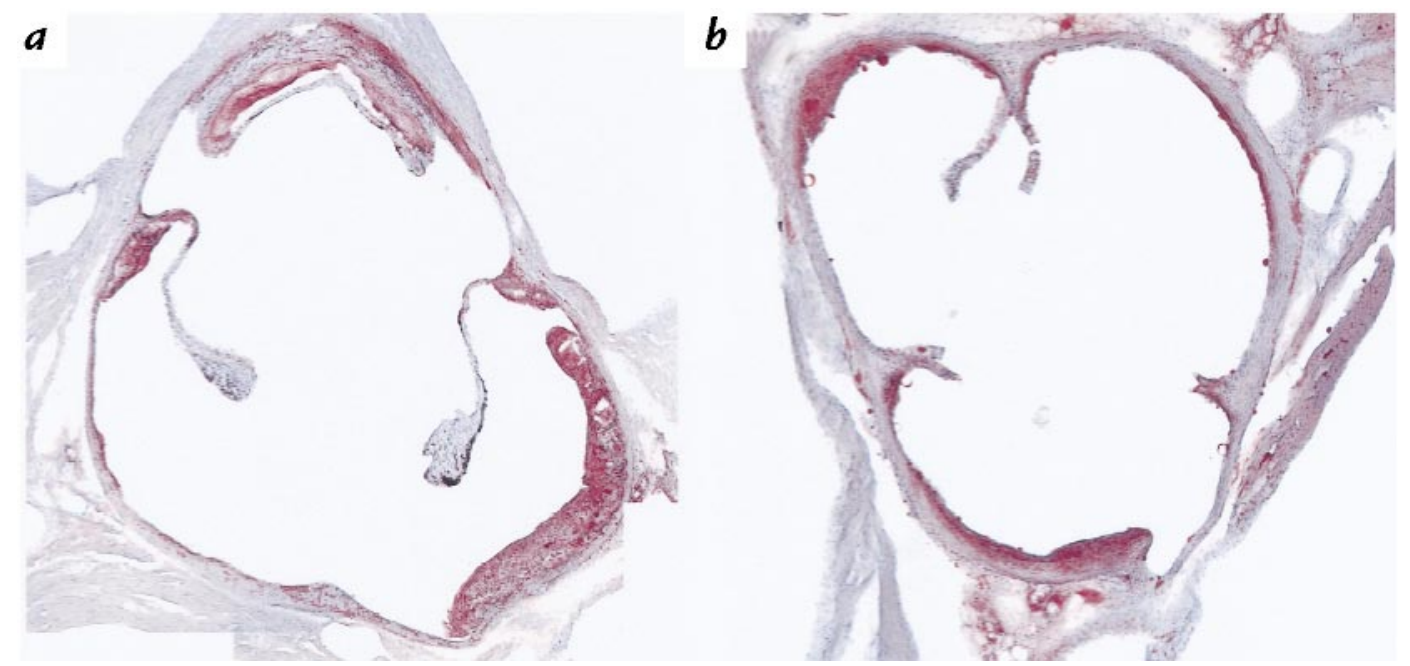

Figure 2

Photomicrographs of proximal aortic lesions in $\mathrm{MCP}-1^{+/+} \mathrm{HuBTg}^{+/ 0}$ and $\mathrm{MCP}-1^{-/-} \mathrm{HuBTg}^{+/ 0}$ mice maintained on a high-fat diet for 18 weeks. Sections were taken at the level of the coronary artery and stained for lipid with oil red $\mathrm{O}$. (a) $M C P-1^{+/+} \mathrm{HuBTg}^{+/ 0} ;(\boldsymbol{b}) M C P-1^{-/-} \mathrm{HuBTg}^{+/ 0}$. Shown are representative images from the data presented in Fig. 1. Original magnification $\times 70$. 

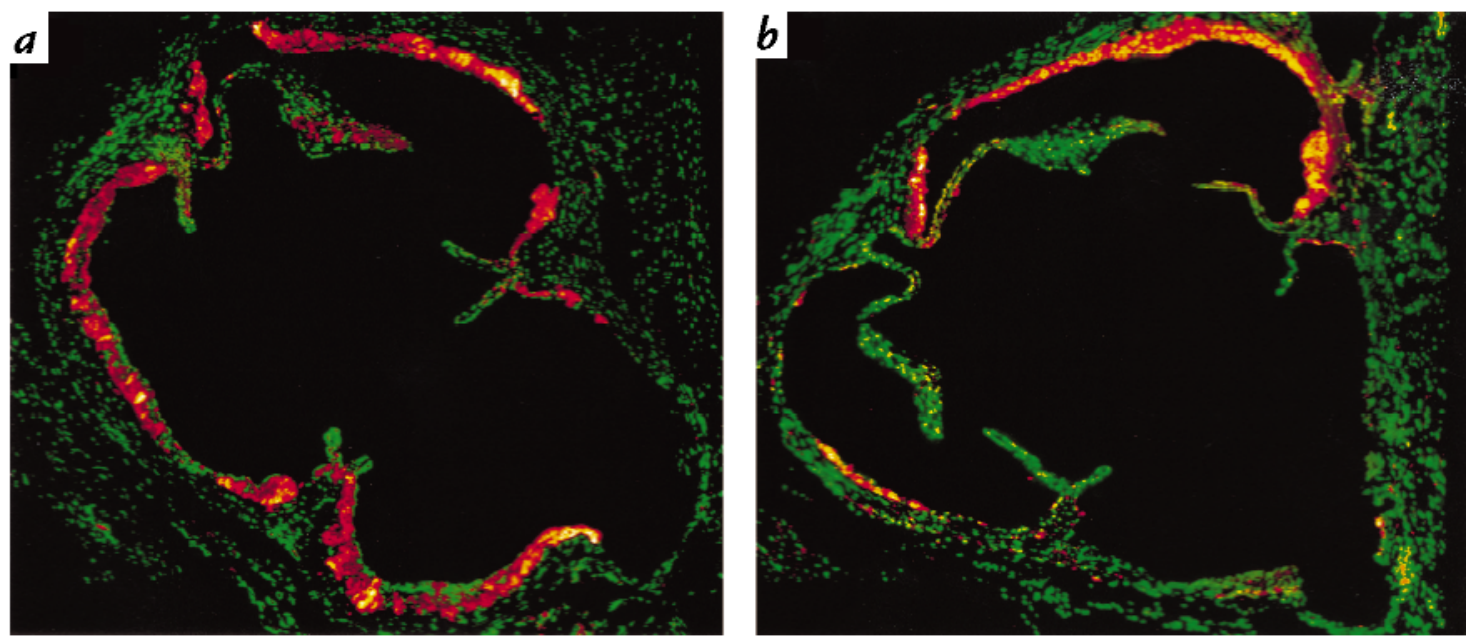

Figure 3

Photomicrographs showing macrophage infiltration of the proximal aorta in MCP-1 ${ }^{+/+} \mathrm{HuBTg}^{+/ 0}$ and $M C P-1^{-/-} \mathrm{HuBTg}^{+/ 0}$ mice maintained on the high-fat diet for 15 weeks. Cross-sections of the aorta at the level of the coronary artery branch were stained for macrophages with MOMA-2 (shown in red) and counterstained for nuclei with SYTOX Green. Regions of overlap appear yellow. (a) $M C P-1^{+/+} \mathrm{HuBTg}^{+/ 0} ;(\boldsymbol{b}) M_{C} P_{-} 1^{-/-} \mathrm{HuBTg} g^{+/ 0}$. Original magnification $\times 130$.

One potentially confounding feature of the study involving LDL receptor-deficient mice was the higher triglyceride level in $L d l r /-M C P-1^{-/}$mice than in $L d l r^{\prime-M C P-1^{+/+}}$mice (14). Triglyceride levels are regulated in part by lipoprotein lipase, which has been implicated in the development of atherosclerotic lesions (43) and is synthesized by vessel wall macrophages (44). Thus, it was difficult to discern whether the changes in triglyceride levels in the Ldlr/-MCP-1/- had a direct role in reducing atheroma formation or merely reflected the failure to recruit macrophages to the vessel wall. Because the plasma triglyceride levels were essentially identical in our two groups of mice, our data indicate that MCP- 1 deficiency must influence atherogenesis by affecting the recruitment of monocytes/macrophages into lesions.

The data in this paper, taken together with recent studies in apo E- and LDL receptor-deficient mice (11, 14), present a compelling argument that activation of CCR2 by MCP-1 plays a central role in the recruitment of monocytes/macrophages to early atherosclerotic lesions. MCP- 1 is synthesized by multiple cells in the vessel wall $(5,6,8)$, and the relative contributions of macrophages, smooth muscle cells, and endothelial cells are not yet clear. In particular, it will be important to determine the extent to which stimulation of MCP1 production by foam cell/macrophages establishes a positive-feedback loop for the recruitment of additional monocytes. It will also be interesting to determine if other chemokines are critical in related but distinct models of vessel disease, such as transplant arteriosclerosis, in which RANTES (45) and MCP-1 (46) are present at high concentrations.

\section{Acknowledgments}

We thank Stephen Ordway and Gary Howard for editorial assistance, John Carroll and Neile Shea for preparation of the figures, David Sanan, Dale Newland, and Lara Jensen for assistance with microscopy and immunohistochemistry, and Kerry Humphrey for manuscript preparation. This study was

\section{Figure 4}

Cholesterol distribution in the plasma lipoprotein fractions of mice with different genotypes. Plasma samples were pooled from groups of mice with the same genotype $(n \geq 4)$ and fractionated on an FPLC column. The cholesterol concentration in each fraction was measured with a colorimetric kit. FPLC, fast-protein liquid chromatography; $H D L$, high-density lipoproteins; IDL, intermediate-density lipoproteins; $L D L$, low-density lipoproteins; $V L D L$, very-low-density lipoproteins.

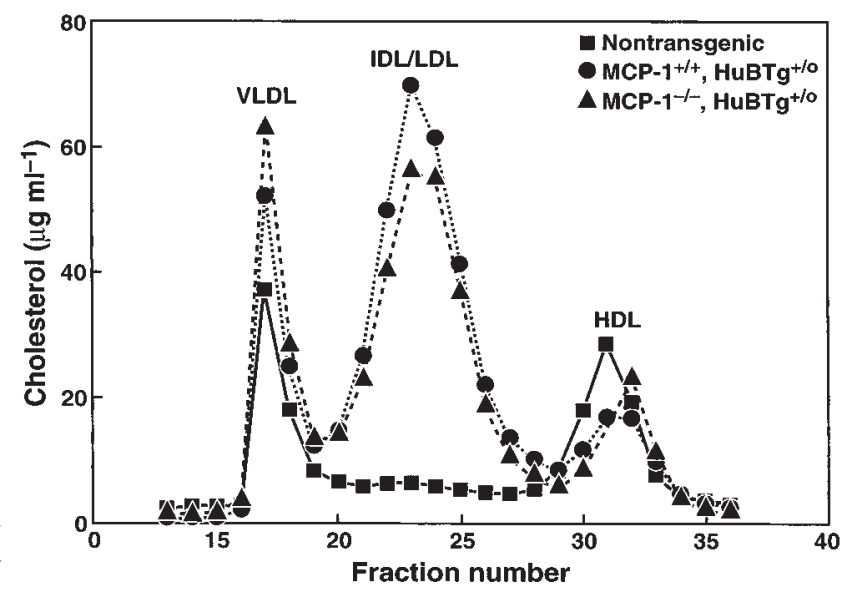


supported in part by National Institutes of Health grants HL-52773 (to I.F. Charo) and HL-41633 (to S.G. Young).

1. Ross, R. 1995. Cell biology of atherosclerosis. Annu. Rev. Physiol. 57:791-804. 2. Gerrity, R.G. 1981. The role of the monocyte in atherogenesis. I. Transition of blood-borne monocytes into foam cells in fatty lesions. Am. J. Pathol. 103:181-190.

3. Faggiotto, A., Ross, R., and Harker, L. 1984. Studies of hypercholesterolemia in the nonhuman primate. I. Changes that lead to fatty streak formation. Arteriosclerosis. 4:323-340.

4. Rollins, B.J. 1997. Chemokines. Blood. 90:909-928.

5. Cushing, S.D., et al. 1990. Minimally modified low density lipoprotein induces monocyte chemotactic protein 1 in human endothelial cells and smooth muscle cells. Proc. Natl. Acad. Sci. USA. 87:5134-5138.

6. Nelken, N.A., Coughlin, S.R., Gordon, D., and Wilcox, J.N. 1991. Monocyte chemoattractant protein-1 in human atheromatous plaques. J. Clin. Invest. 88:1121-1127.

7. Ylä-Herttuala, S., et al. 1991. Expression of monocyte chemoattractant protein 1 in macrophage-rich areas of human and rabbit atherosclerotic lesions. Proc. Natl. Acad. Sci. USA. 88:5252-5256.

8. Yu, X., et al. 1992. Elevated expression of monocyte chemoattractant protein 1 by vascular smooth muscle cells in hypercholesterolemic primates. Proc. Natl. Acad. Sci. USA. 89:6953-6957.

9. Piedrahita, J.A., Zhang, S.H., Hagaman, J.R., Oliver, P.M., and Maeda, N. 1992. Generation of mice carrying a mutant apolipoprotein $\mathrm{E}$ gene inactivated by gene targeting in embryonic stem cells. Proc. Natl. Acad. Sci. USA. 89:4471-4475.

10. Plump, A. S., et al. 1992. Severe hypercholesterolemia and atherosclerosis in apolipoprotein E-deficient mice created by homologous recombination in ES cells. Cell. 71:343-353.

11. Boring, L., Gosling, J., Cleary, M., and Charo, I.F. 1998. Decreased lesion formation in CCR2 $2^{--}$mice reveals a role for chemokines in the initiation of atherosclerosis. Nature. 394:894-897.

12. Ishibashi, S., et al. 1993. Hypercholesterolemia in low density lipoprotein receptor knockout mice and its reversal by adenovirus-mediated gene delivery. J. Clin. Invest. 92:883-893.

13. Ishibashi, S., Goldstein, J.L., Brown, M.S., Herz, J., and Burns, D.K. 1994. Massive xanthomatosis and atherosclerosis in cholesterol-fed low density lipoprotein receptor-negative mice. J. Clin. Invest. 93:1885-1893.

14. Gu, L., et al. 1998. Absence of monocyte chemoattractant protein-1 reduces atherosclerosis in low density lipoprotein receptor-deficient mice. Mol. Cell. 2:275-281.

15. Linton, M.F., et al. 1993. Transgenic mice expressing high plasma concentrations of human apolipoprotein B100 and lipoprotein(a). J. Clin. Invest. 92:3029-3037.

16. Purcell-Huynh, D.A., et al. 1995. Transgenic mice expressing high levels of human apolipoprotein B develop severe atherosclerotic lesions in response to a high-fat diet. J. Clin. Invest. 95:2246-2257.

17. Kim, E., and Young, S.G. 1998. Genetically modified mice for the study of apolipoprotein B. J. Lipid Res. 39:703-723.

18. Nishina, P.M., Verstuyft, J., and Paigen, B. 1990. Synthetic low and high fat diets for the study of atherosclerosis in the mouse. J. Lipid Res. 31:859-869.

19. Farese, R.V., Jr., Ruland, S.L., Flynn, L.M., Stokowski, R.P., and Young, S.G. 1995. Knockout of the mouse apolipoprotein B gene results in embryonic lethality in homozygotes and protection against diet-induced hypercholesterolemia in heterozygotes. Proc. Natl. Acad. Sci. USA. 92:1774-1778.

20. Young, S.G., Smith, R.S., Hogle, D.M., Curtiss, L.K., and Witztum, J.L. 1986. Two new monoclonal antibody-based enzyme-linked assays of apolipoprotein B. Clin. Chem. 32:1484-1490

21. Young, S.G., Bertics, S.J., Curtiss, L.K., Casal, D.C., and Witztum, J.L. 1986. Monoclonal antibody MB19 detects genetic polymorphism in human apolipoprotein B. Proc. Natl. Acad. Sci. USA. 83:1101-1105.

22. Young, S.G., Witztum, J.L., Casal, D.C., Curtiss, L.K., and Bernstein, S. 1986 Conservation of the low density lipoprotein receptor-binding domain of apoprotein B: demonstration by a new monoclonal antibody, MB47. Arteriosclerosis. 6:178-188.

23. Zlot, C.H., et al. 1999. Generation of monoclonal antibodies specific for mouse apolipoprotein B-100 in apolipoprotein B-48-only mice.J. Lipid Res. 40:76-84.

24. Raabe, M., et al. 1998. Knockout of the abetalipoproteinemia gene in mice: reduced lipoprotein secretion in heterozygotes and embryonic lethality in homozygotes. Proc. Natl. Acad. Sci. USA. 95:8686-8691.

25. Kim, E., Lowenson, J.D., MacLaren, D.C., Clarke, S., and Young, S.G. 1997.
Deficiency of a protein-repair enzyme results in the accumulation of altered proteins, retardation of growth, and fatal seizures in mice. Proc. Natl. Acad. Sci. USA. 94:6132-6137.

26. Kim, E., Cham, C.M., Véniant, M.M., Ambroziak, P., and Young, S.G. 1998 Dual mechanisms for the low plasma levels of truncated apolipoprotein B proteins in familial hypobetalipoproteinemia: analysis of a new mouse model with a nonsense mutation in the Apob gene. J. Clin. Invest. 101:1468-1477.

27. Véniant, M.M., et al. 1997. Susceptibility to atherosclerosis in mice expressing exclusively apolipoprotein B48 or apolipoprotein B100. J. Clin. Invest. 100:180-188.

28. Rubin, E.M., Ishida, B.Y., Clift, S.M., and Krauss, R.M. 1991. Expression of human apolipoprotein A-I in transgenic mice results in reduced plasma levels of murine apolipoprotein A-I and the appearance of two new high density lipoprotein size subclasses. Proc. Natl. Acad. Sci. USA. 88:434-438.

29 Pászty, C., Maeda, N., Verstuyft, and Rubin, E.M. 1994. Apolipoprotein A-I transgene corrects apolipoprotein E deficiency-induced atherosclerosis in mice. J. Clin. Invest. 94:899-903.

30. Liu, A.C., Lawn, R.M., Verstuyft, J.G., and Rubin, E.M. 1994. Human apolipoprotein A-I prevents atherosclerosis associated with apolipoprotein[a] in transgenic mice. J. Lipid Res. 35:2263-2267.

31. Nielsen, L.B., et al. 1997. Human apolipoprotein B transgenic mice generated with 207 - and 145-kilobase pair bacterial artificial chromosomes. Evidence that a distant 5 -element confers appropriate transgene expression in the intestine. J. Biol. Chem. 272:29752-29758.

32. Paigen, B., Morrow, A., Brandon, C., Mitchell, D., and Holmes, P. 1985. Variation in susceptibility to atherosclerosis among inbred strains of mice. Atherosclerosis. 57:65-73.

33. Paigen, B., Morrow, A., Holmes, P.A., Mitchell, D., and Williams, R.A. 1987. Quantitative assessment of atherosclerotic lesions in mice. Atherosclerosis. 68:231-240

34. Paigen, B., Albee, D., Holmes, P.A., and Mitchell, D. 1987. Genetic analysis of murine strains $\mathrm{C} 57 \mathrm{BL} / 6 \mathrm{~J}$ and $\mathrm{C} 3 \mathrm{H} / \mathrm{HeJ}$ to confirm the map position of Ath-1, a gene determining atherosclerosis susceptibility. Biochem. Genet. 25:501-511.

35. Reddick, R.L., Zhang, S.H., and Maeda, N. 1994. Atherosclerosis in mice lacking apo E: evaluation of lesional development and progression. Arterioscler. Thromb. 14:141-147.

36. Zhang, S.H., Reddick, R.L., Piedrahita, J.A., and Maeda, N. 1992. Spontaneous hypercholesterolemia and arterial lesions in mice lacking apolipoprotein E. Science. 258:468-471.

37. Nakashima, Y., Plump, A.S., Raines, E.W., Breslow, J.L., and Ross, R. 1994. Apo E-deficient mice develop lesions of all phases of atherosclerosis throughout the arterial tree. Arterioscler. Thromb. 14:133-140.

38. Tangirala, R.K., Rubin, E.M., and Palinski, W. 1995. Quantitation of atherosclerosis in murine models: correlation between lesions in the aortic origin and in the entire aorta, and differences in the extent of lesions between sexes in LDL receptor-deficient and apolipoprotein E-deficient mice. J. Lipid Res. 36:2320-2328.

39. Sniderman, A., et al. 1980. Association of coronary atherosclerosis with hyperapobetalipoproteinemia: increased protein but normal cholesterol levels in human plasma low density ( $\beta$ ) lipoproteins. Proc. Natl. Acad. Sci. USA. 77:604-608.

40. Teng, B., Sniderman, A.D., Soutar, A.K., and Thompson, G.R. 1986. Metabolic basis of hyperapobetalipoproteinemia: turnover of apolipoprotein B in low density lipoprotein and its precursors and subfractions compared with normal and familial hypercholesterolemia. J. Clin. Invest. 77:663-672.

41. Sniderman, A., Brown, B.G., Stewart, B.F., and Cianflone, K. 1992. From familial combined hyperlipidemia to hyperapoB: unravelling the overproduction of hepatic apolipoprotein B. Curr. Opin. Lipidol. 3:137-142.

42. Callow, M.J., Verstuyft, J., Tangirala, R., Palinski, W., and Rubin, E.M. 1995. Atherogenesis in transgenic mice with human apolipoprotein B and lipoprotein (a). J. Clin. Invest. 96:1639-1646.

43. Goldberg, I.J. 1996. Lipoprotein lipase and lipolysis: central roles in lipoprotein metabolism and atherogenesis. J. Lipid Res. 37:693-707.

44. Ylä-Herttuala, S., et al. 1991. Macrophages and smooth muscle cells express lipoprotein lipase in human and rabbit atherosclerotic lesions. Proc. Natl. Acad. Sci. USA. 88:10143-10147.

45. Pattison, J.M., Nelson, P.J., Huie, P., Sibley, R.K., and Krensky, A.M. 1996. RANTES chemokine expression in transplant-associated accelerated atherosclerosis. J. Heart Lung Transplant. 15:1194-1199.

46. Russell, M.E., et al. 1993. Early and persistent induction of monocyte chemoattractant protein 1 in rat cardiac allografts. Proc. Natl. Acad. Sci. USA. 90:6086-6090. 